\title{
Debris mitigation techniques for petawatt-class lasers in high debris environments
}

\author{
Jens Schwarz, * Patrick Rambo, Mark Kimmel, Matthias Geissel, Grafton Robertson, Marc Ramsey, \\ Daniel Headley, and Briggs Atherton \\ Sandia National Laboratories, P.O. Box 5800, Albuquerque, New Mexico 87185-1193, USA
}

(Received 13 November 2009; published 20 April 2010)

\begin{abstract}
This paper addresses debris mitigation techniques for two different kinds of debris sources that are found in the high-energy density community. The first debris source stems from the laser-target interaction and this debris can be mitigated by avoiding a direct line of sight to the debris source (e.g. by using a sacrificial fold mirror) or by inserting a thin debris shield. Several thin film debris shields have been investigated and nitrocellulose was found to be the best suited. The second debris source originates from an external high-energy density driver or experiment. In our specific case, this is the $Z$ accelerator, a $Z$-pinch machine that generates $2 \mathrm{MJ}$ of $\mathrm{x}$ rays at $300 \mathrm{TW}$. The center section of the $Z$ accelerator is an extremely violent environment which requires the development of novel debris mitigation approaches for backlighting with petawatt lasers. Two such approaches are presented in this paper. First, a self-closing focusing cone. In our facility, the focused beam on target is fully enclosed inside a solid focusing cone. In the first debris mitigation scenario, the last part of the cone has a "flapper" that should seal the cone when the pressure wave from the $Z$-pinch explosion hits it. In the second scenario, an enclosed target assembly is used, with the last part of the focusing cone connected to a "target can" which houses the laser target. The laser produced $x$ rays for backlighting escape through a $3 \mathrm{~mm}$ diameter hole that is protected by an $\mathrm{x}$-ray filter stack. Both techniques are discussed in detail and have been successfully tested on the $Z$ accelerator.
\end{abstract}

DOI: 10.1103/PhysRevSTAB.13.041001

PACS numbers: 52.59.Qy

\section{INTRODUCTION}

Laser-target experiments involving high energy, high intensity lasers can generate a considerable amount of debris that can contaminate the final focusing optics [16]. One way to mitigate this is to maximize the incident angle between laser propagation direction and target normal. However, over time, more and more debris will be collected on the focusing optic which lowers performance and will lead to damage over time $[7,8]$. For high power lasers, these optics are very expensive and fabrication time can be on the order of years. In most applications a debris shield is used to protect the final focusing optic from contaminants [9]. The thickness of the debris shield is limited by the nonlinear phase that is accumulated in transmission [10]. This is expressed by the $B$ integral:

$$
B=\frac{2 \pi}{\lambda} \int_{0}^{L} I n_{2} d l
$$

where $\lambda$ is the laser wavelength, $I$ is the laser intensity, $n_{2}$ the nonlinear index of the material (e.g. $2.7 \times$ $10^{-16} \mathrm{~cm}^{2} / \mathrm{W}$ for fused silica [11]), and $L$ the thickness of the debris shield. As a rule of thumb, the added $B$ integral should stay below 1.5. For ns scale, terawatt class systems $B$ integral limits debris shields to thicknesses on the order of centimeters while, for ps scale, petawatt-class systems the thickness is limited to submillimeter. At

\footnotetext{
*jschwar@sandia.gov
}

Sandia's $Z$ backlighter laser facility, a $1 \mathrm{~cm}$ thick, fused silica debris shield is used to protect the final focusing lens of the Z-beamlet laser (ZBL) [12] from the explosive fragments (see Fig. 1) that are generated by the $Z$ accelerator [13]. This electrical pulsed power machine generates $2 \mathrm{MJ}$ of $Z$-pinch $\mathrm{x}$ rays at $300 \mathrm{TW}$ for a variety of highenergy density applications. Since $2001, Z$ beamlet $(2 \mathrm{~kJ}$, $2 \mathrm{~ns}$ at $527 \mathrm{~nm}$ ) has been used to $\mathrm{X}$-ray backlight these $Z$-pinch events at photon energies up to $6 \mathrm{keV}$. Recently, the Z-petawatt laser (ZPW) [14] (500 J, $500 \mathrm{fs}$ at $1054 \mathrm{~nm}$ ) has been added to the facility in order to increase time resolution, to decrease motional blurring, and to boost the $\mathrm{x}$-ray backlighting energy up to $25 \mathrm{keV}$.

In the ZPW case, according to Eq. (1), the debris shield thickness is limited to less than $500 \mu \mathrm{m}$ for fused silica if the accumulated nonlinear phase is to stay below 1.5. From Fig. 1 it is clear that a submillimeter debris shield cannot sufficiently protect the final focusing parabola of a petawatt laser. Laser-target debris consists of a small amount of metal vapor which will not damage the optic on a singleshot basis, but will sputter the surface and degrade performance over time. The debris expected from a Z-pinch event, on the other hand, is not well understood. A large mass of metal is vaporized in an explosive event, and the character of the debris varies depending on the particular target load. The mass or velocity distribution of the debris has never been studied in detail. However, at a qualitative level it is clear that the debris exists in several forms. The earliest debris can be assumed to consist of metal vapor and 

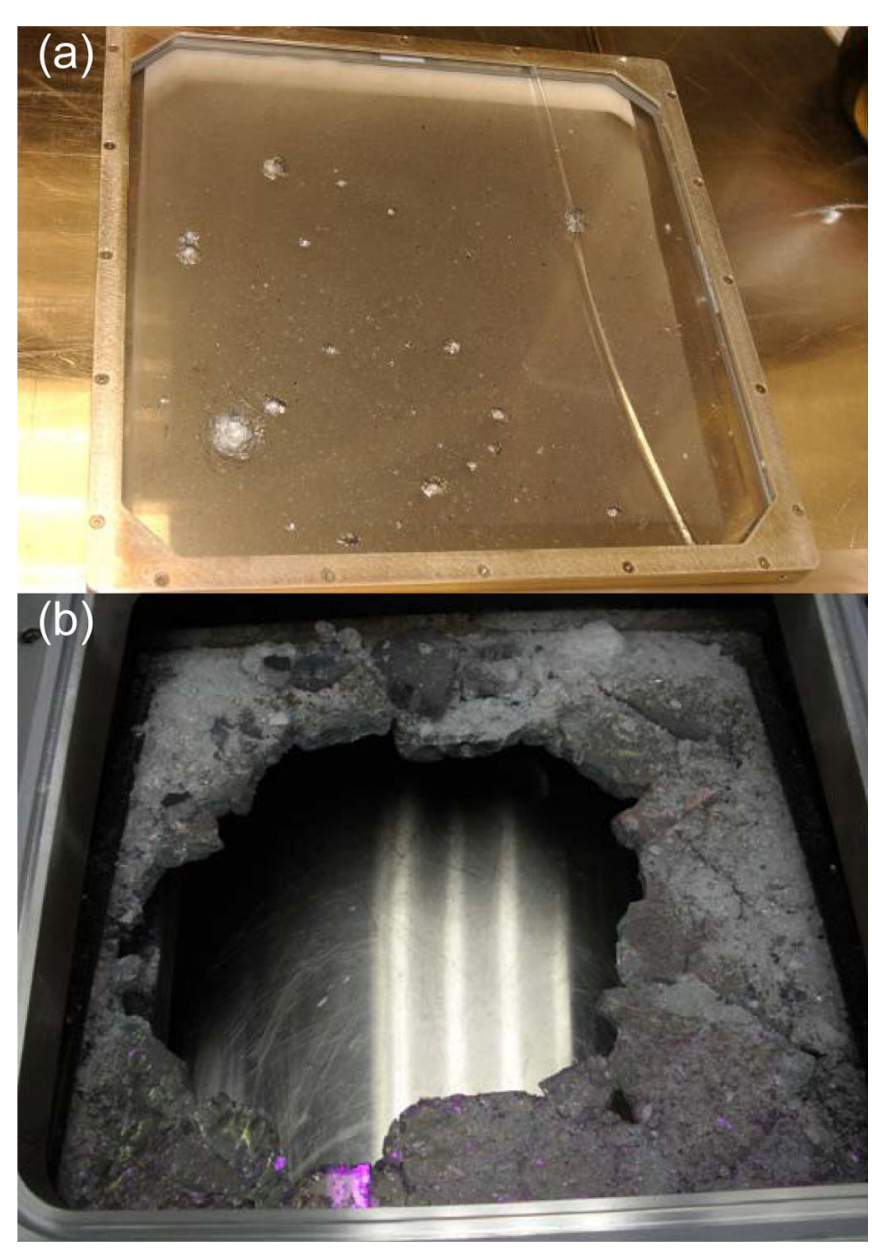

FIG. 1. (Color) (a) Typical ZBL fused silica debris shield after a single shot on the $Z$ accelerator. (b) Debris shield from a recent ZBL shot into the $Z$ accelerator. In this configuration, there was a more direct line of sight between the $Z$-pinch event and the laser debris shield. Hence, the debris shield showed even more damage than in (a). ZBL debris shields are exchanged for every shot.

is believed to have a velocity of $5-10 \mathrm{~km} / \mathrm{s}$. This is followed by droplets of molten metal, which are thought to compose the bulk of the debris. Presumably latest in time are massive solid projectiles which routinely embed themselves in the walls of the $Z$ chamber. Those "large debris" velocities have been estimated to be below $100 \mathrm{~m} / \mathrm{s}$. To protect ZPW against these various classes of debris, a multi-element approach has been adopted.

\section{DEBRIS MITIGATION TECHNIQUES}

Figure 2 shows a schematic of the ZPW final optics assembly (FOA) on top of the $Z$ accelerator. The $43 \mathrm{~cm}$ diameter petawatt beam hits the off-axis parabola $(75 \mathrm{~cm}$ diameter, $60^{\circ}$ off-axis $f / \#=11$ ) before it is reflected to a steering mirror and subsequently focused onto a target in the center section of the $Z$ accelerator. At laser intensities of up to $10^{20} \mathrm{~W} / \mathrm{cm}^{2}$ on target, this creates strong $k$-shell $\mathrm{x}$-ray emissions at $10 \mathrm{~cm}$ distance from the $Z$ load. These

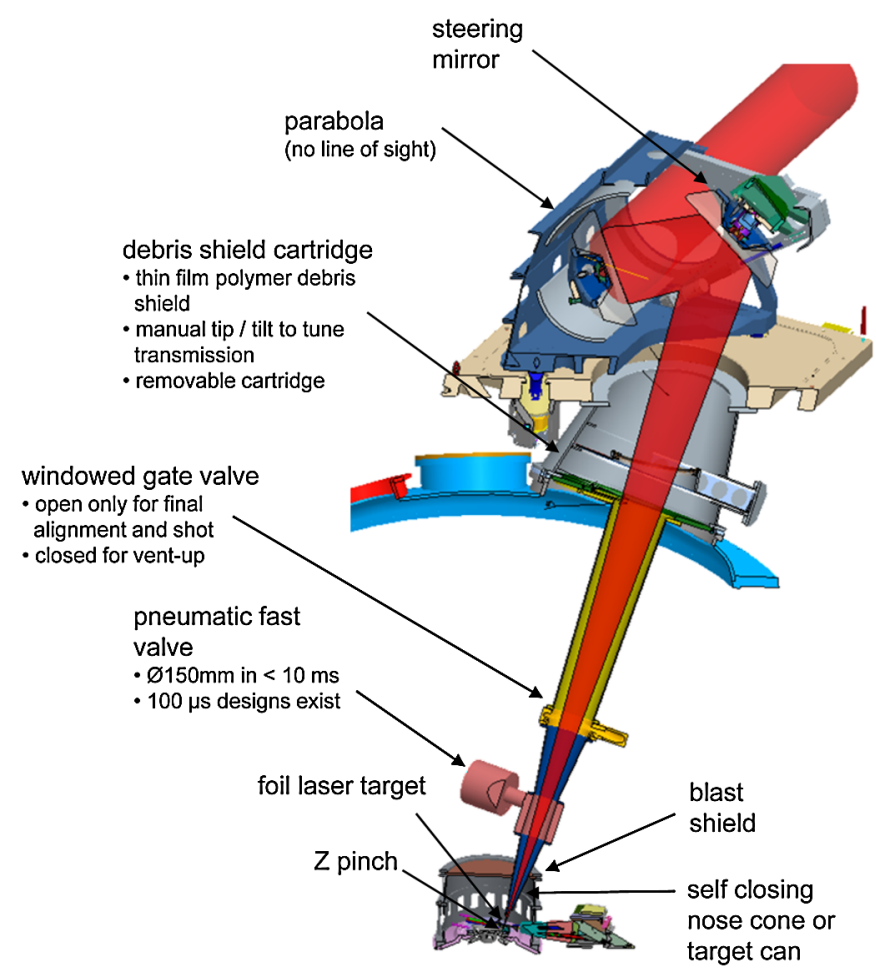

FIG. 2. (Color) Schematic of the FOA on top of the $Z$ machine.

high-energy $\mathrm{x}$ rays are then used to backlight the $Z$-pinch event.

\section{A. Avoiding direct line of sight}

Since the laser target is located $10 \mathrm{~cm}$ off to the side with respect to the $Z$ pinch, there is no direct line of sight between the FOA and the $Z$ pinch. To further minimize the chance of debris hitting the parabola, the entire focusing cone is enclosed in $3.2 \mathrm{~mm}$ thick aluminum.

Two approaches have been considered to prevent debris from entering the focusing cone: (i) self-closing focusing cone-in this scenario the last part of the cone has a "flapper" that should seal the cone when the pressure wave from the Z-pinch explosion hits it (see Fig. 3); (ii) enclosed target assembly-in this case, the last part of the focusing cone is connected to a "target can" which houses the laser target. The laser produced $\mathrm{x}$ rays for backlighting escape through a $3 \mathrm{~mm}$ diameter hole that is protected by an $\mathrm{x}$-ray filter stack. Both techniques are designed to prevent debris from directly reaching the FOA optics. However, there will be slower, secondary debris which needs to be captured.

\section{B. Fast closing shutter}

A fast moving, $15 \mathrm{~cm}$ diameter pneumatic shutter (VAT series 75) is used to catch slower, secondary debris up in the focusing cone. Its closing time and jitter were studied under vacuum conditions. For test purposes, the fast valve was closed off by $15 \mathrm{~cm}$ diameter viewports and evacuated 


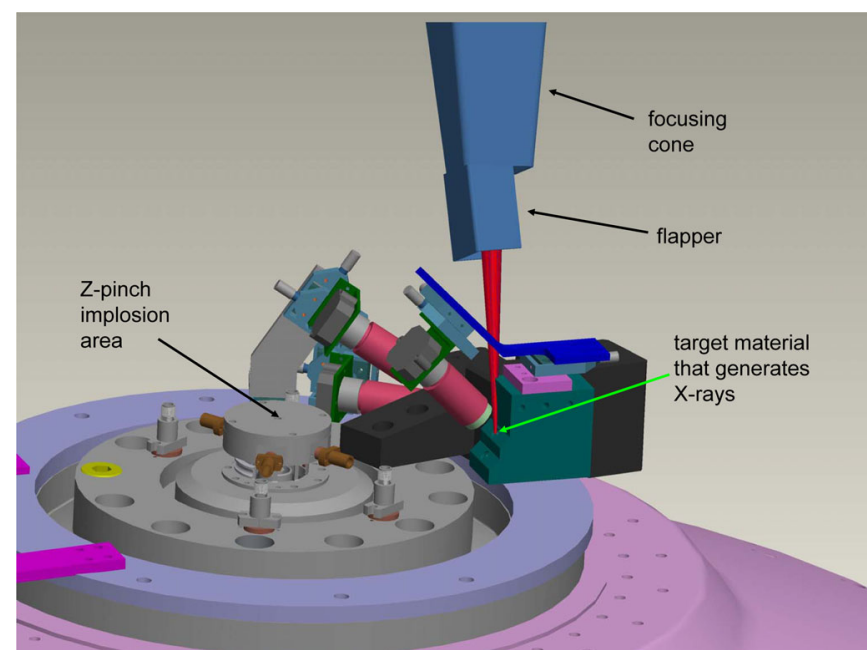

FIG. 3. (Color) Schematic of the $Z$ center section. The incoming laser beam is enclosed all the way up to the target. When the $Z$-pinch debris hits the flapper it should self-close and prevent debris from entering the focusing cone.

to a pressure of 17 mTorr. Two $4.5 \mathrm{~mW}$ green diode lasers were placed in such a way that they barely skimmed the top and bottom of the valve cross section. The transmitted light was collected with two photodiodes and sent into an oscilloscope. In an open valve configuration, a constant DC offset voltage is displayed on the scope. A trigger channel from a delay generator provides the trigger for the valve closure and a synchronous output supplies a time fiducial for the oscilloscope. Once the valve is triggered it first blocks the upper beam (detected by the blue trace) and subsequently the lower beam (red trace) as can be seen in Fig. 4. A total of 36 valve closures were performed (see

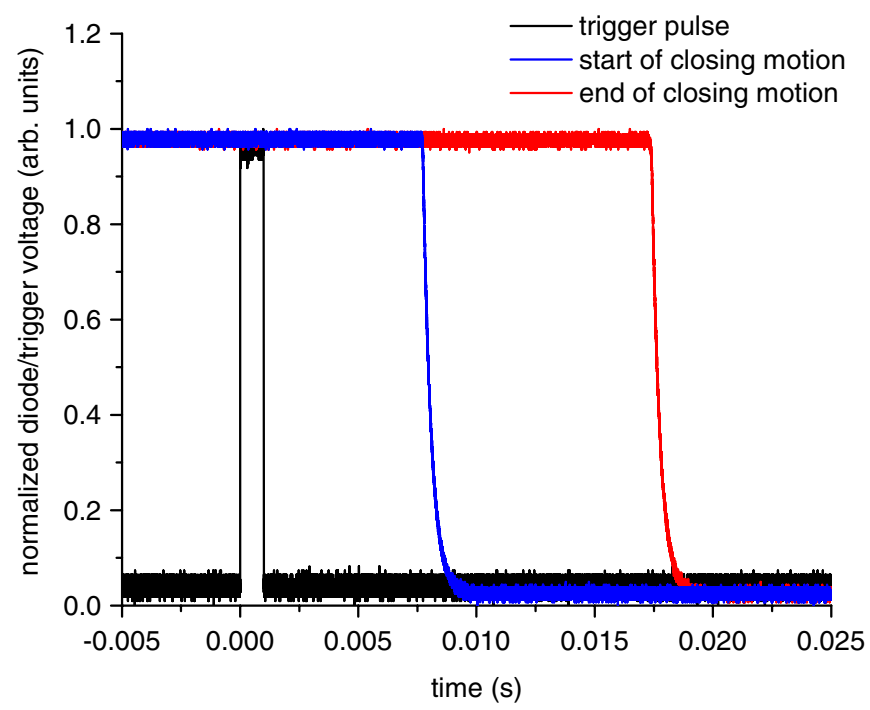

FIG. 4. (Color) Normalized trigger and diode traces. The rising edge of the black trace indicates the valve trigger event, the blue trace shows the onset of valve closure, and the red curve indicates full valve closure.

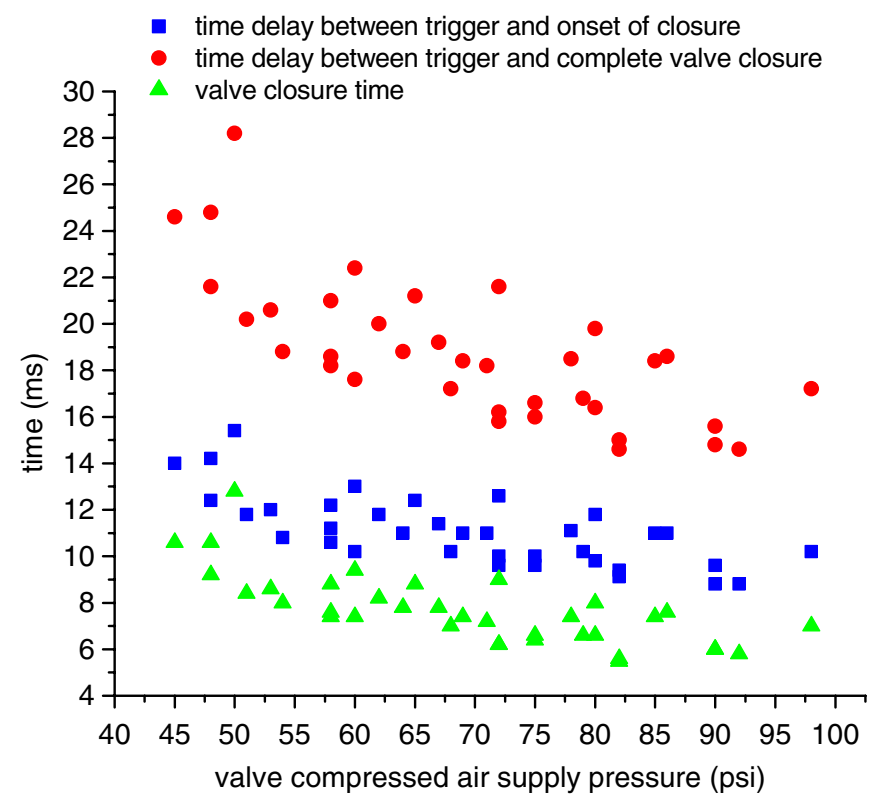

FIG. 5. (Color) Valve closure time versus valve supply pressure. The blue squares show the time delay between valve trigger and the onset of closure, the red circles display the time delay between valve trigger and complete valve closure, and the green triangles show the difference between the two (valve closure time).

Fig. 5). One can see that the closing behavior is roughly the same for valve supply pressures above 70 psi. Below that value, the valve closing performance degrades to the extent that the valve should not be operated in that regime. At pressures above $70 \mathrm{psi}$, the shortest total delay between the valve trigger and the onset of valve closure was $8.8 \mathrm{~ms}$ and the longest delay was measured to be $12.6 \mathrm{~ms}$, leading to a maximum jitter of $3.8 \mathrm{~ms}$. The average valve closure time was measured to be $(6.7 \pm 0.9) \mathrm{ms}$. At an average closing time of $6.7 \mathrm{~ms}$, and a distance of $65 \mathrm{~cm}$ from the fast valve to the $z$ pinch, the valve can stop direct line of sight debris with a velocity of less than $60-100 \mathrm{~m} / \mathrm{s}$. This would be in an extreme case where the final focusing cone would be destroyed by z-pinch debris. Realistically, the debris would "rattle" around multiple times inside the focusing cone meaning that the valve would catch debris with much higher initial velocities.

\section{Thin film debris shield}

The fastest, low mass gaseous debris certainly cannot be stopped with a mechanical shutter, suggesting the need for a transmissive debris shield. As mentioned earlier, $B$-integral considerations restrict the thickness of the debris shield to less than $500 \mu \mathrm{m}$. A debris shield needs to exhibit good surface quality and good transmission characteristics while tolerating high fluence levels $\left(\approx 1 \mathrm{~J} / \mathrm{cm}^{2}\right)$, all at large aperture ranging from 30 to $60 \mathrm{~cm}$ diameter. Furthermore, it should have mechanical rigidity to withstand small $Z$-pinch debris. Based on this, a 
TABLE I. List of materials that were studied as well as their long pulse damage threshold (LP DT), short pulse damage threshold (SP DT) and AR coated SP DT.

\begin{tabular}{|c|c|c|c|c|c|}
\hline Material & Thickness & Test dimension & LP DT & SP DT & SP DT AR coated \\
\hline Nitrocellulose & $1.77 \mu \mathrm{m}$ & $15.24 \mathrm{~cm}$ diameter & $2-12 \mathrm{~J} / \mathrm{cm}^{2}$ & $2.5 \mathrm{~J} / \mathrm{cm}^{2}$ & $2.2 \mathrm{~J} / \mathrm{cm}^{2}$ \\
\hline Mylar & $1.5 \mu \mathrm{m}$ & $15 \mathrm{~cm} \times 30 \mathrm{~cm}$ & & & \\
\hline Polyimide & $0.5 \mu \mathrm{m}$ & $17.8 \mathrm{~cm}$ diameter & $2.5-5 \mathrm{~J} / \mathrm{cm}^{2}$ & $0.133 \mathrm{~J} / \mathrm{cm}^{2}$ & \\
\hline
\end{tabular}

robust short pulse debris shield out of a polymeric membrane is considered. Nitrocellulose, Mylar, and polyimide were investigated (see Table I) with respect to their optical and spectral transmission quality, absorption, stress induced birefringence, and damage threshold. A detailed discussion can be found in [15].

The spectral transmission measurements [15] show the expected thin film interference patterns with nitrocellulose and polyimide having peak transmissions of nearly $100 \%$ at $1054 \mathrm{~nm}$ and Mylar showing a peak transmission of only $93 \%$ at the same wavelength. For that reason Mylar was eliminated as a possible debris shield candidate. Measurements on nitrocellulose and polyimide showed no stress induced birefringence and no significant transmitted wavefront distortions ( $\leq \lambda / 8$ peak to valley and $\leq \lambda / 50 \mathrm{rms}$ ) due to their small thickness.

Long pulse laser damage testing was performed by Spica Technologies Inc. who followed the Lawrence Livermore National Laboratories's National Ignition Facility (NIF) damage testing specification NIF-5008633 (MEL01-013OD). Samples were tested using a Q-switched Nd:YAG laser at $1064 \mathrm{~nm}$ with a pulse width of $3.5 \mathrm{~ns}$ FWHM and a spot diameter of $1.07 \mathrm{~mm}$ at $1 / e^{2}$. The multimode laser had a $\mathrm{TEM}_{00}$ beam profile with an incident angle of $0^{\circ}$ at a repetition rate of $5 \mathrm{~Hz}$. A total of 2000 spots were illuminated for any given test fluence. The highest nondamage fluence for nitrocellulose was $11.5 \mathrm{~J} / \mathrm{cm}^{2}$ and the lowest nondamage fluence was $2 \mathrm{~J} / \mathrm{cm}^{2}$. However, less than $0.5 \%$ of the laser test sites showed damage up to a fluence of about $30 \mathrm{~J} / \mathrm{cm}^{2}$. For polyimide the damage threshold was around $2.5-5 \mathrm{~J} / \mathrm{cm}^{2}$ with a much steeper rise in the number of damage sites than nitrocellulose as the fluence increased. In addition, polyimide showed catastrophic damage at $20 \mathrm{~J} / \mathrm{cm}^{2}$ whereas nitrocellulose did not.

Short pulse vacuum laser damage testing was performed by our group at Sandia National Laboratories [16]. The $460 \mathrm{fs}$ FWHM laser beam was focused with a 1-meter focal length lens to a focal spot size of $110 \mu \mathrm{m}$ at $1 / e^{2}$ inside a vacuum chamber at a pressure of $5 \times 10^{-6}$ torr during damage testing. A beam splitter inside the vacuum chamber sampled the laser beam, sending it through a viewport to an external CCD camera which monitored the laser beam spot size at the focus. A sample holder, manipulated with a motorized $\mathrm{XYZ}$ translation stage, was placed in the chamber at the focus of the laser beam. Damage regions were created on the thin film sample in a $10 \times 10$ grid, representing ten steps of increasing laser energy, and ten single laser shots at each energy step. The spacing of the elements within the $10 \times 10$ grid was $100 \mu \mathrm{m}$. Damage was observed ex situ with a Zeiss optical microscope fitted with an AxioCam camera and AxioVision image analysis software. Short pulse damage thresholds obtained in this test are lower by an order of magnitude compared to similar tests performed at Spica, as one would expect based upon pulse width dependence on laser damage threshold. Testing samples of similar properties, we report single-shot short pulse laser damage thresholds of $2.5 \mathrm{~J} / \mathrm{cm}^{2}$ for nitrocellulose and $0.133 \mathrm{~J} / \mathrm{cm}^{2}$ for polyimide thin films. Based on this data, one can clearly see that nitrocellulose is best suited for our application. A $43.2 \mathrm{~cm}$ diameter debris shield has been fabricated by National Photocolor Inc. and was used for the debris tests discussed here. Initially it was proposed to use the thin film interference properties of nitrocellulose in order to tune the film thickness to where a transmission peak occurs exactly at $1054 \mathrm{~nm}$. However, this would require a thickness control of $\pm 20 \mathrm{~nm}$ over the full aperture of the debris shield. Several tests showed that this was not achievable. Instead an antireflection (AR) coating was applied to both sides of the film that covered a laser bandwidth from 1050-1060 nm and laser incident angles from $(26 \pm 3)^{\circ}$. Figure 6 shows a spectrophotometer trace of an AR coated debris shield. As one can see, the spectral transmission is above $97 \%$ across all angles and

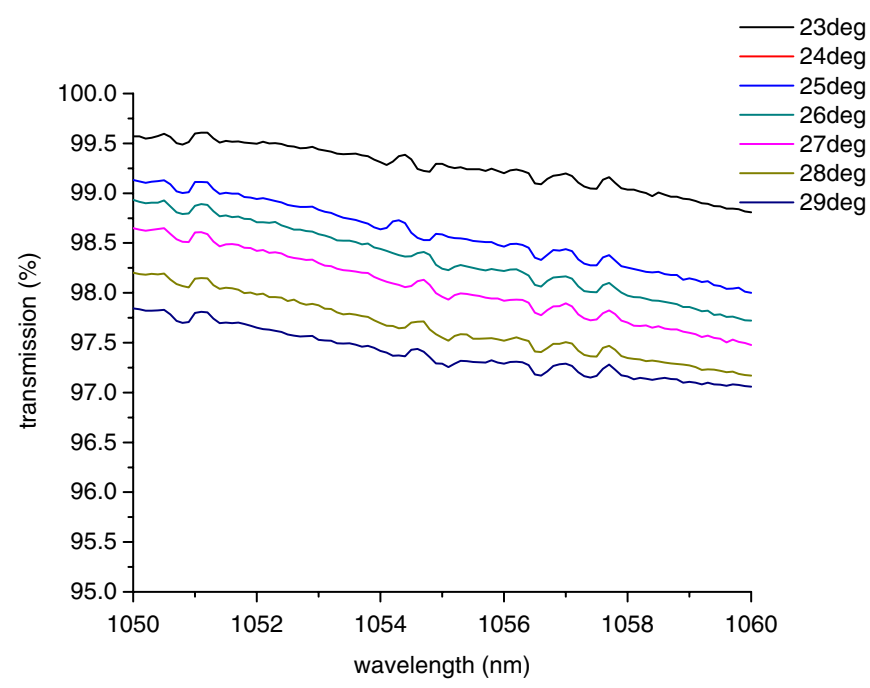

FIG. 6. (Color) Spectral transmission through AR coated nitrocellulose at various angles of incidence and a wavelength bandwidth of $10 \mathrm{~nm}$. 
over the complete laser bandwidth. At the central wavelength and main incident angle the transmission is around $98.5 \%$. In house short pulse damage testing on the AR coated nitrocellulose showed damage thresholds of $2.2 \mathrm{~J} / \mathrm{cm}^{2}$ which is well above the $300 \mathrm{~mJ} / \mathrm{cm}^{2}$ of fluence in the ZPW beam.

\section{EXPERIMENTAL RESULTS}

\section{Self-closing focusing cone}

Debris tests on $Z$ were performed without the FOA optics in place to verify the debris mitigation functionality without risk to costly optics. An aluminum plate sealed off the lid of the $Z$ accelerator and had multiple $25.4 \mathrm{~mm}$ diameter nitrocellulose witness samples mounted to the bottom surface.

The final focusing cone was made of $3.2 \mathrm{~mm}$ thick copper that had been joined by 20 equally spaced $3.2 \mathrm{~mm}$ steel rivets and a weld of the outer edge to the underlying stock. Figure 7 shows a successful test of such a cone

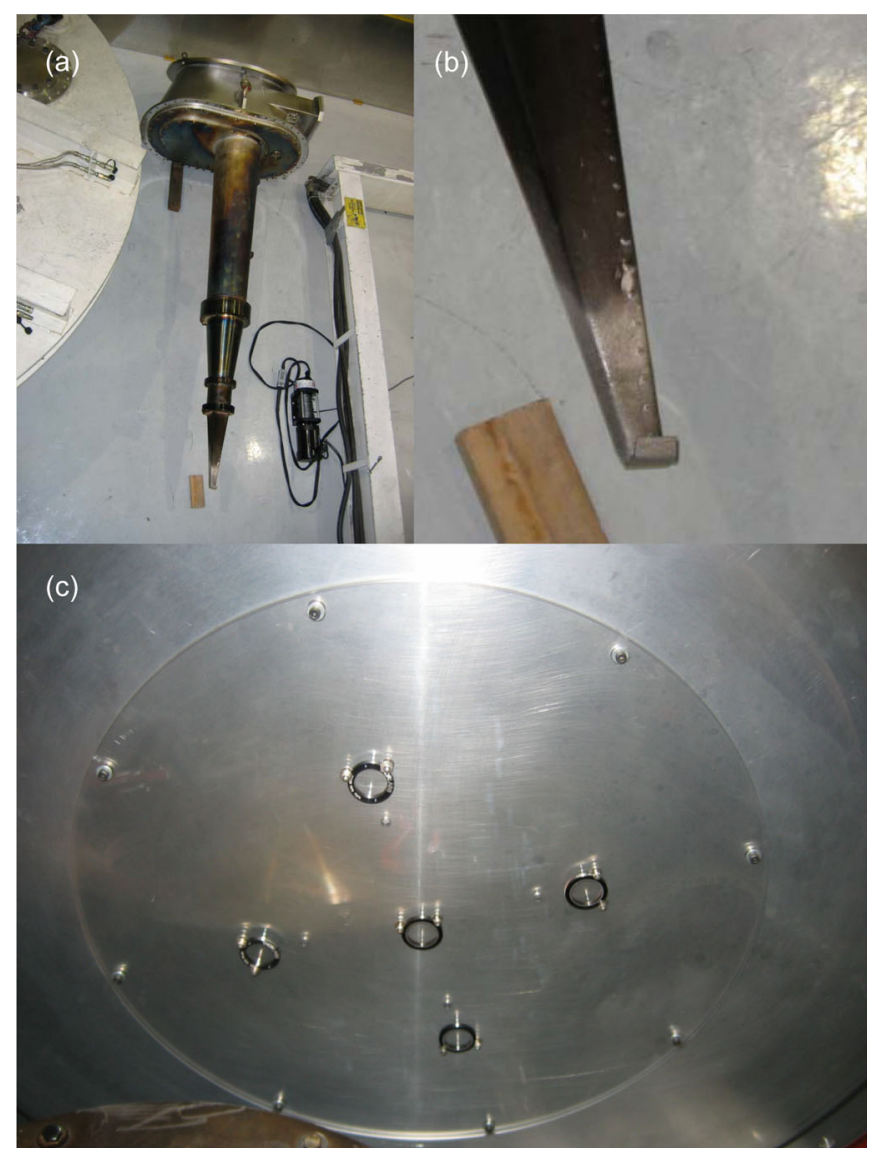

FIG. 7. (Color) (a) Complete FOA focusing cone after a $Z$ shot. (b) Enlarged lower focusing cone. One can see that the rivets are facing away from the debris source and that the flapper closed properly on this shot. (c) View up into the focusing cone. All nitrocellulose samples are intact and in pristine condition. No dust is visible on the nitrocellulose or on the aluminum base plate. which had the weld facing away from the $Z$-pinch target. One can see that the flapper closed properly [7(a) and 7(b)] and that the nitrocellulose test samples further up the cone [7(c)] are in good condition. No dust particles were visible on the thin film or the aluminum face plate.

\section{B. Enclosed target assembly}

A further improvement to the self-closing focusing cone is the enclosed target assembly or target can. In this scenario, the laser-target interaction volume is enclosed in a stainless steel box that is $150 \mathrm{~mm}$ wide, $100 \mathrm{~mm}$ tall, and $75 \mathrm{~mm}$ deep with $6 \mathrm{~mm}$ thick walls on the front and $12 \mathrm{~mm}$ thick walls elsewhere (see Fig. 8). The front face of the box has a $3 \mathrm{~mm}$ diameter hole that allows the laser generated $\mathrm{x}$ rays to escape.

Four tapped mounting holes on the front side can accept an $x$-ray filter stack which is designed to transmit $25 \mathrm{keV}$ laser generated $\mathrm{x}$ rays while still guarding against $Z$ debris. Kapton and beryllium were chosen as $\mathrm{x}$-ray filters since they are mechanically very strong materials with high $\mathrm{x}$ ray transmission. While beryllium is stronger, it has the disadvantages of toxicity and being more brittle, which poses the risk of shattering on impact. Two alternating layers of beryllium and the more elastic kapton were therefore chosen to maximize total strength and limit propagation of impact driven cracks. Despite its higher absorption, a single layer of aluminum was put on top as a sacrificial heat shield. The filter stack then looks as follows (in order from outside to inside): $250 \mu \mathrm{m}$ aluminum, $250 \mu \mathrm{m}$ beryllium, $1 \mathrm{~mm}$ kapton, $250 \mu \mathrm{m}$ beryllium, and $1 \mathrm{~mm}$ kapton. All filters are $12 \mathrm{~mm} \times 12 \mathrm{~mm}$ square and are wrapped inside $24 \mu \mathrm{m}$ of aluminum foil. The relative $25 \mathrm{keV}$ transmission coefficients for $250 \mu \mathrm{m}$ material are kapton $/ 98.9 \%, \mathrm{Al} / 89.4 \%$, and $\mathrm{Be} / 99.2 \%$ [17], which results in a total filter transmission of $80.6 \%$.

Tests were performed with the fast shutter and the full size $43.2 \mathrm{~cm}$ diameter nitrocellulose debris shield in place.

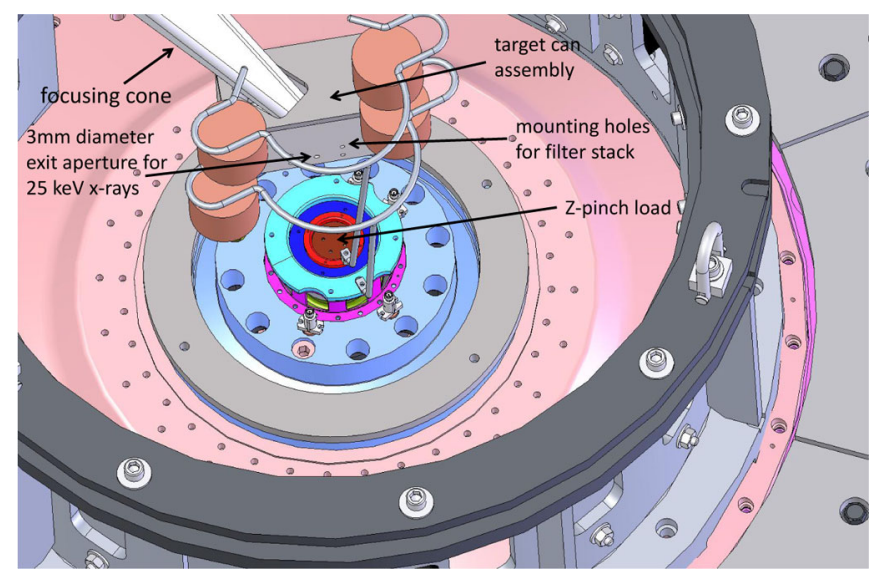

FIG. 8. (Color) Computer-aided design model of the $Z$-center section. One can see the final focusing cone as it enters the target can. 


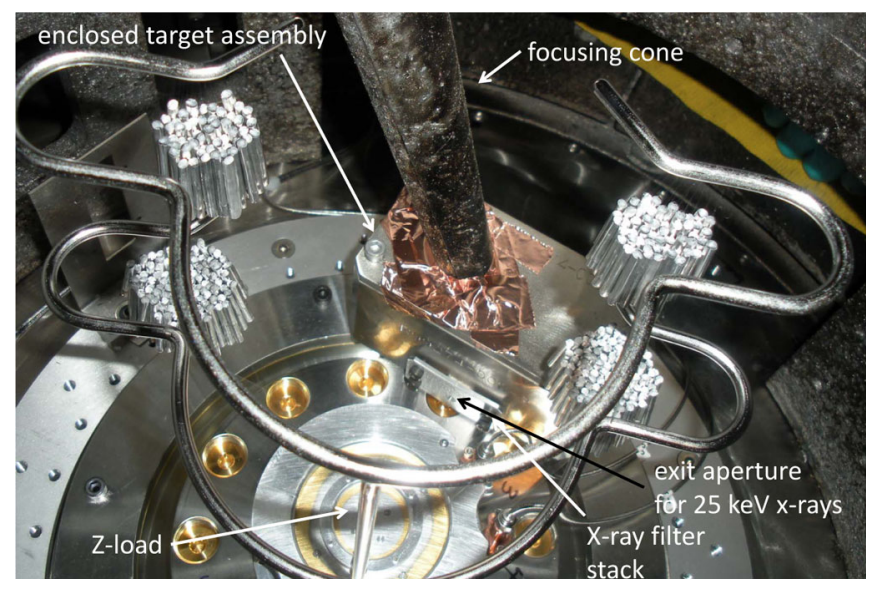

FIG. 9. (Color) Fully installed target can inside the Z-center section. The laser light is guided through the focusing cone into the target housing where it generates $\mathrm{x}$ rays that can escape through the filtered $3 \mathrm{~mm}$ exit hole.

Figure 9 shows the actual setup inside the $Z$-center section. One can see that the laser beam is fully enclosed with no direct line of sight from the $Z$ pinch to the focusing parabola. As of now, the setup has been fielded on two consecutive $Z$ shots with the debris shield surviving both of these tests. The focusing cone was heavily covered with debris after the first shot but did not show signs of puncture. It could be reused for the second test, in which it also survived intact. The pellicle debris shield showed no signs of coating contamination or dust particles on its surface and was reused for the second debris test (which it survived). However, the debris shield structurally failed during the post-shot venting procedure. This procedure had been optimized to mitigate pressure differentials on either side of the debris shield and the vent-up should not have caused failure. A "fresh" debris shield can "bulge" under pressure to about $10 \mathrm{~cm}$ saggitus. After this shot, however, the pellicle ruptured immediately at the onset of the slow

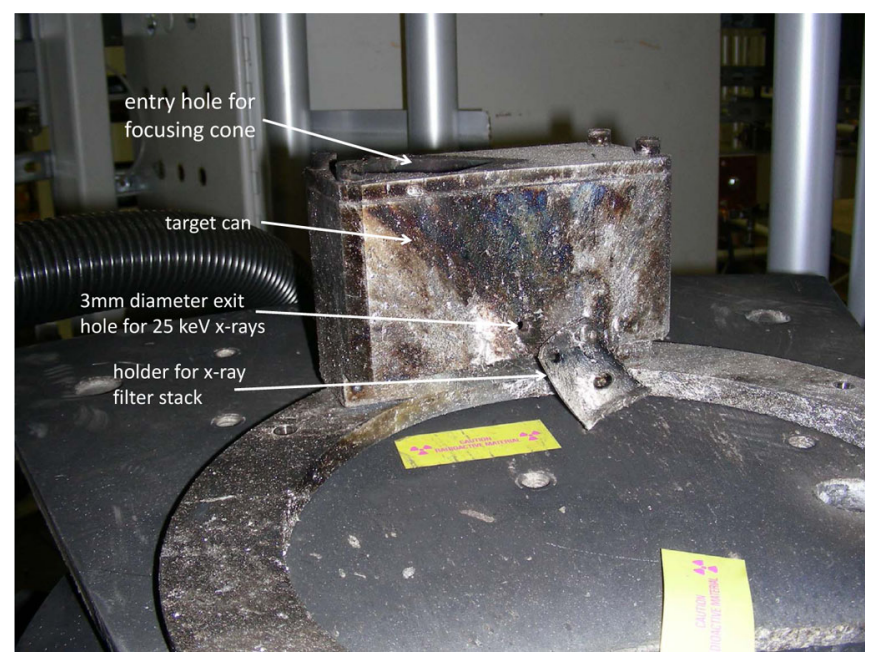

FIG. 10. (Color) Target can after a $Z$ shot. venting procedure. This may indicate that the nitrocellulose was structurally modified by hot gaseous vapor or $Z$-pinch generated $x$ rays. Figure 10 shows the target can after the $Z$ shot. One can observe that the surface is heavily coated with debris (mostly molten metal) and that the filter stack is missing (probably shattered or vaporized). The cover plate of the filter stack is barely holding on to the slightly deformed box. This assembly is not reusable and needs replacement for every shot.

\section{CONCLUSION}

We have presented and successfully tested two different debris mitigation techniques that are suited for high debris environments. While the self-closing focusing cone method is conceptually simple, it has also a much higher risk of failure and may not be suitable for medium to low debris environments. The enclosed target can method however is much more reliable and should be applicable to a large variety of laser-target focusing geometries. More successful debris tests are needed before the final focusing optics may be installed on a ZPW backlighting shot.

\section{ACKNOWLEDGMENTS}

Sandia is a multiprogram laboratory operated by Sandia Corporation, a Lockheed Martin Company, for the United States Department of Energy's National Nuclear Security Administration under Contract No. DE-AC04-94AL85000.

[1] A.E. Koniges et al., J. Phys. Conf. Ser. 112, 032072 (2008).

[2] James E. Andrew, Proc. SPIE Int. Soc. Opt. Eng. 5991, 59911K1 (2005).

[3] J. Andrew, B. Rus, J. Griffiths, R. Heathcote, and D. Neely, Proc. SPIE Int. Soc. Opt. Eng. 5647, 322 (2005).

[4] J. D. Griffiths and J.E. Andrew, Proc. SPIE Int. Soc. Opt. Eng. 5991, L9910 (2005).

[5] James E. Andrew, Karen R. Mann, Michael T. Tobin, and Joe C. Watson, Proc. SPIE Int. Soc. Opt. Eng. 4932, 147 (2003).

[6] Howard Bender, Ann Marie P. Eligon, D. O'Connell, and William T. Silfvast, in Applications of Laser Plasma Radiation (SPIE, San Diego, CA, 1994), Vol. 2015, pp. 113-117.

[7] Joe C. Watson, James E. Andrew, and Nicholas J. Bazin, Proc. SPIE Int. Soc. Opt. Eng. 4932, 76 (2003).

[8] F. Rainer, A. Anderson, A. Burnham, D. Milam, and R. Turner, Proc. SPIE Int. Soc. Opt. Eng. 2966, 463 (1997).

[9] Y. Kitagawa, H. Fujita, R. Kodama, H. Yoshida, S. Matsuo, T. Jitsuno, T. Kawasaki, H. Kitamura, T. Kanabe, S. Sakabe, K. Shigemori, N. Miyanaga, and Y. Izawa, IEEE J. Quantum Electron. 40, 281 (2004).

[10] D. M. Pennington, C. G. Brown, T.E. Cowan, S.P. Hatchett, E. Henry, S. Herman, M. Kartz, M. Key, J. Koch, A. J. MacKinnon, M.D. Perry, T. W. Phillips, M. Roth, T. C. Sangster, M. Singh, R. A. Snavely, M. Stoyer, 
B. C. Stuart, and S. C. Wilks, IEEE J. Sel. Top. Quantum Electron. 6, 676 (2000).

[11] D. Milam and M. J. Weber, J. Appl. Phys. 47, 2497 (1976).

[12] P. K. Rambo, I. C. Smith, J. L. Porter, M. J. Hurst, C. S. Speas, R. G. Adams, A.J. Garcia, E. Dawson, B.D. Thurston, C. Wakefield, J. W. Kellogg, M. J. Slattery, H. C. Ives, R. S. Broyles, J.A. Caird, A.C. Erlandson, J.E. Murray, W.C. Behrendt, N.D. Neilsen, and J.M. Narduzzi, Appl. Opt. 44, 2421 (2005).

[13] M. K. Matzen, B.W. Atherton, M.E. Cuneo, G. L. Donovan, C. A. Hall, M. Herrmann, M. L. Kiefer, R. J. Leeper, G. T. Leifeste, F. W. Long, G. R. McKee, T. A. Mehlhorn, J. L. Porter, L.X. Schneider, K. W. Struve, W. A. Stygar, and E. A. Weinbrecht, Acta Phys. Pol. A 115(6), 956 (2009).
[14] Jens Schwarz, Patrick Rambo, Matthias Geissel, Aaron Edens, Ian Smith, Erik Brambrink, Mark Kimmel, and Briggs Atherton, J. Phys. Conf. Ser. 112, 032020 (2008).

[15] Jens Schwarz, Patrick Rambo, Matthias Geissel, Daniel Headley, Marc Ramsey, and Briggs Atherton, in LaserInduced Damage in Optical Materials: 2007 (SPIE, Boulder, CO, 2007), Vol. 6720, pp. 67200Q-10.

[16] Mark Kimmel, Jens Schwarz, Patrick Rambo, Matthias Geissel, and Briggs Atherton, in Laser-Induced Damage in Optical Materials: 2008 (SPIE, Boulder, CO, 2008), Vol. 7132, pp. 713210-9.

[17] Lawrence Berkeley National Laboratories Center for Xray Optics, http://www.cxro.lbl.gov/. 